\title{
SELF-REGULATED LEARNING IN CORRELATION TO LEARNING OUTCOME OF COMPUTER-BASED TEST PREPARATION OF MEDICAL STUDENTS
}

\author{
Ade Pryta R. Simaremare ${ }^{1 *}$ \\ ${ }^{1}$ Divisi Assessment Fakultas Kedokteran Universitas HKBP Nommensen, Medan - INDONESIA
}

\begin{abstract}
Background: After the preclinical and clinical phase, medical students have to pass the Uji Kompetensi Mahasiswa Program Profesi Dokter (UKMPPD) consisting the computer-based test (CBT) and objective structured clinical examination (OSCE). In preparation of the examinations, the student should follow tutoring activity. During the process, the student will be given try outs to measure the learning outcome. This study aimed to measure the self-regulated learning in correlation to learning outcome of Computer-based test of May 2018 batch preparation participants in Medan.

Methods: This was an observational correlation analytic study with cross sectional method and 204 respondents collected. The self-regulated learning score obtained using a questionaire and the learning outcome obtained from the try out scores average gained by the respondents.

Result: This study revealed that most of the participants represented bad in self-regulated learning $(72,1 \%)$. The metacognition aspect mainly represented in bad $(55,9 \%)$, the motivation aspect mainly represented in bad (77\%), however, the behaviour aspect mainly represented in good (51,5\%). The learning outcomes mainly represented in fail $(87,3 \%)$. According to chi square test, this study showed that there was no correlation between self-regulated learning and learning outcome of students prepared for the CBT of May 2018 batch in Medan ( $p$ value = 0,731).

Conclusion: Learning outcome affected by many factors. The students ability of learning, thinking, and problem solving affected by adaptation in values, beliefs, and customs that evolved in their social and cultural environment. Furthermore, it also affected by self confidence, motivation and learning purposes.
\end{abstract}

Keywords: medical student, computer-based test, self-regulated learning, learning outcome

\begin{abstract}
ABSTRAK
Latar belakang: Setelah menjalani fase pendidikan akademik dan profesi, mahasiswa kedokteran harus lulus dari Uji Kompetensi Mahasiswa Program Profesi Dokter (UKMPPD) yaitu computer-based test (CBT) dan objective structured clinical examination (OSCE). Dalam persiapan menghadapi ujian tersebut, mahasiswa akan mengikuti proses bimbingan baik dari internal kampus maupun dari lembaga bimbingan belajar eksternal. Selama proses pembimbingan, mahasiswa akan diberikan try out yang merupakan gambaran hasil belajarnya selama ini. Penelitian ini bertujuan untuk mengetahui apakah terdapat hubungan selfregulated learning (SRL) mahasiswa dengan hasil belajar mahasiswa yang mempersiapkan diri untuk ujian CBT periode Mei 2018 di kota Medan.

Metode: Penelitian ini menggunakan disain analitik korelasi observasional dengan metode cross sectional dan jumlah responden sebanyak 204 orang. Nilai SRL diperoleh dari kuesioner dan hasil belajar diperoleh dari rerata nilai try out yang diikuti oleh responden.
\end{abstract}

*corresponding author, contact: adepryta.mare@gmail.com 
Hasil: Penelitian ini menunjukkan sebagian besar responden memiliki SRL yang buruk (72,1\%). Aspek metakognisi sebagian besar pada kategori buruk (55,9\%), aspek motivasi sebagian besar pada kategori buruk $(77 \%)$, dan aspek perilaku sebagian besar pada kategori baik (51,5\%). Hasil belajar sebagian besar menunjukkan hasil tidak lulus $(87,3 \%)$. Berdasarkan uji chi square, hasil penelitian menunjukkan tidak terdapat hubungan antara SRL dengan hasil belajar mahasiswa yang mempersiapkan diri untuk ujian CBT periode Mei 2018 di kota Medan ( $\mathrm{p}=0,731$ ).

Kesimpulan: Hasil belajar dipengaruhi oleh banyak faktor. Kemampuan seseorang untuk belajar, berpikir dan menyelesaikan masalah belajar dipengaruhi oleh adaptasi terhadap nilai-nilai, kepercayaan, kebiasaan yang berkembang dalam lingkungan sosial dan budaya mereka. Selain itu juga dipengaruhi oleh keyakinan diri, motivasi dan tujuan belajarnya.

Kata kunci: mahasiswa kedokteran, computer-based test, self-regulated learning, hasil belajar

\section{PENDAHULUAN}

Mahasiswa fakultas kedokteran pada masa pendidikannya menjalani dua fase yaitu pendidikan akademik dan pendidikan profesi. Hal ini sesuai dengan Undang-Undang Republik Indonesia Nomor 20 Tahun 2013 Tentang Pendidikan Kedokteran. Setelah menjalani kedua tahap pendidikan tersebut, mahasiswa tersebut juga harus mengikuti ujian tahap akhir yaitu Uji Kompetensi Mahasiswa Program Profesi Dokter (UKMPPD). ${ }^{1}$ Ujian ini terdiri atas ujian teori dalam bentuk computer-based test (CBT) dan ujian keterampilan klinis dalam objective structured clinical examination (OSCE). Kelulusan dalam ujian ini merupakan syarat untuk memperoleh sertifikat profesi untuk selanjutnya dapat dipergunakan untuk tahap internship.

Persiapan untuk menghadapi ujian ini dapat berupa pembimbingan intensif internal yang diselenggarakan oleh institusi tempat mahasiswa tersebut terdaftar, maupun dari lembaga bimbingan eksternal yang khusus untuk mempersiapkan mahasiswa-mahasiswa yang akan mengikuti ujian tersebut. Selama proses bimbingan, para peserta akan diberikan latihan pengerjaan soal-soal seperti pada ujian yang sebenarnya dalam bentuk try out untuk mengetahui perkembangan hasil pembelajarannya baik secara pribadi maupun selama mengikuti pembimbingan. Penelitian yang dilakukan oleh Meri terhadap mahasiswa di Fakultas Kedokteran Abulyatama menunjukkan bahwa proses bimbingan belajar memiliki hubungan yang signifikan terhadap kelulusan Computer-based test tersebut. ${ }^{2,3}$

Hasil belajar akan sangat dipengaruhi oleh faktor eksternal yang berasal dari luar diri dan faktor internal yang berasal dari dalam diri mahasiswa bersangkutan. Faktor eksternal yaitu latar belakang keluarga, lingkungan, dan instrumen belajar, sedangkan faktor internal yaitu fisiologis (kondisi jasmani) dan psikologis (minat, bakat, kecerdasan, dan kemampuan kognitif) dari mahasiswa tersebut., ${ }^{4}$ Individu yang belajar akan memperoleh hasil yang baik bila ia menyadari, bertanggungjawab dan mengetahui cara belajar yang efektif atau memiliki strategi regulasi diri dalam belajar (self-regulated learning, SRL) yang baik.

Self-regulated learning merupakan kegiatan dimana seseorang belajar secara aktif, menyusun, menentukan tujuan belajar, merencanakan dan memonitor, mengatur dan mengontrol kognisi, motivasi perilaku serta lingkungannya untuk mencapai tujuan yang telah ditetapkannya sendiri. ${ }^{6}$ Penelitian yang dilakukan oleh Siti terhadap mahasiswa di Malang menunjukkan bahwa mahasiswa yang diberi pelatihan SRL memiliki prestasi akademik yang lebih tinggi dibandingkan mahasiswa yang tidak diberi pelatihan SRL.? Namun, penelitian yang dilakukan oleh Supriyanto menunjukkan bahwa tidak ada hubungan yang signifikan antara SRL dengan prestasi akademik pada mahasiswa semester pertama Prodi Psikologi Universitas Pembangunan Jaya. ${ }^{8}$ 
Berdasarkan latar belakang tersebut, penulis ingin meneliti apakah terdapat hubungan antara SRL dengan hasil belajar pada mahasiswa yang mempersiapkan diri untuk ujian CBT periode Mei 2018 di kota Medan.

\section{METODE}

Penelitian ini menggunakan desain penelitian analitik korelasi observasional dengan metode penelitian cross-sectional. Responden dalam penelitian ini diperoleh dari suatu lembaga bimbingan belajar persiapan CBT di kota Medan. Penelitian dilaksanakan pada bulan Maret - Mei 2018. Pada penelitian ini terdapat variabel bebas dan variabel terikat. Yang menjadi variabel bebas adalah SRL yang diukur dengan menggunakan kuesioner dengan 48 pertanyaan metode likert sangat setuju (SS) hingga tidak pernah (TP), sedangkan yang menjadi variabel terikat adalah hasil belajar mahasiswa yang diukur dari rerata nilai try out CBT yang diikuti pada periode persiapan kelas reguler di lembaga bimbingan tersebut.

Nilai SRL dikategorikan baik bila skor penilaian $\geq 170$, kategori buruk bila skor penilaian $\leq 169$. Penjabaran dari SRL yaitu aspek metakognisi, aspek motivasi, dan aspek perilaku. Penilaian aspek metakognisi yaitu kategori baik bila skor $>91$ dan buruk bila skor $\leq 91$; penilaian aspek motivasi yaitu kategori baik bila skor $>40,5$ dan buruk bila skor $\leq 40,5$; penilaian aspek perilaku yaitu kategori baik bila skor $>34,5$ dan buruk bila skor $\leq 34,4$. Hasil belajar dikategorikan lulus bila rerata nilai try out $\geq$ 67 dan tidak lulus bila rerata nilai try out $<67$.

Data karakteristik peserta bimbingan (usia, jenis kelamin, asal FK, frekuensi ujian), data hasil try out CBT dan penilaian SRL ditampilkan dalam tabel distribusi frekuensi. Analisis bivariat dilakukan untuk melihat hubungan SRL dengan hasil belajar (nilai try out) mahasiswa yang sedang mempersiapkan diri untuk ujian CBT periode Mei 2018 di kota Medan. Uji hipotesis yang digunakan adalah uji Chi-square.

\section{HASIL DAN PEMBAHASAN \\ Deskripsi Karakteristik Mahasiswa Peserta Bimbingan Persiapan CBT Periode Mei 2018}

Responden yang diperoleh pada penelitian ini adalah mahasiswa yang mengikuti bimbingan persiapan UKMPPD di suatu lembaga bimbingan sebanyak 204 orang yang telah memenuhi kriteria inklusi dan eksklusi. Lembaga bimbingan ini menerima peserta bimbingan kelas regular dari berbagai institusi Fakultas Kedokteran di Sumatera Utara maupun luar Sumatera Utara baik swasta maupun negeri, baik laki-laki maupun perempuan, persiapan untuk ujian yang pertama kali maupun yang retaker. Distribusi frekuensi dari karakteristik mahasiswa peserta bimbingan persiapan CBT Periode Mei 2018 di lembaga bimbingan tersebut telah dirangkumkan dalam Tabel 1.

Tabel 1. Distribusi Frekuensi Jenis Kelamin, Frekuensi Mengikuti Ujian CBT, dan Asal Institusi FK Responden

\begin{tabular}{|c|c|c|}
\hline Karakteristik & Frekuensi (orang) & Persentase (\%) \\
\hline $\begin{array}{l}\text { Jenis Kelamin } \\
\text { - Laki-laki } \\
\text { - Perempuan }\end{array}$ & $\begin{array}{r}56 \\
148\end{array}$ & $\begin{array}{l}27,5 \\
72,5\end{array}$ \\
\hline $\begin{array}{l}\text { Frekuensi Mengikuti Ujian CBT } \\
\text { - } 1 \mathrm{x} \\
-3 \mathrm{x}\end{array}$ & $\begin{array}{r}201 \\
3\end{array}$ & $\begin{array}{r}98,5 \\
1,5\end{array}$ \\
\hline
\end{tabular}


Asal Institusi FK

- FK Univ. HKBP Nommensen (UHN)

- FK Univ. Islam Sumatera Utara (UISU)

$\begin{array}{cc}4 & 2 \\ 98 & 48 \\ 20 & 9,8 \\ 3 & 1,5 \\ 4 & 2 \\ 2 & 1 \\ 21 & 10,3 \\ 52 & 25,5\end{array}$

\section{Deskripsi Self-Regulated Learning Mahasiswa Peserta Bimbingan Persiapan CBT Periode Mei 2018}

Kepada 204 responden dibagikan kuesioner SRL, kemudian dikumpulkan dan datanya diolah untuk memberikan deskripsi univariat mengenai frekuensi kategori baik dan buruk dari SRL dan aspek-aspeknya. Hasil deskripsi tersebut telah dirangkumkan pada Gambar 1.

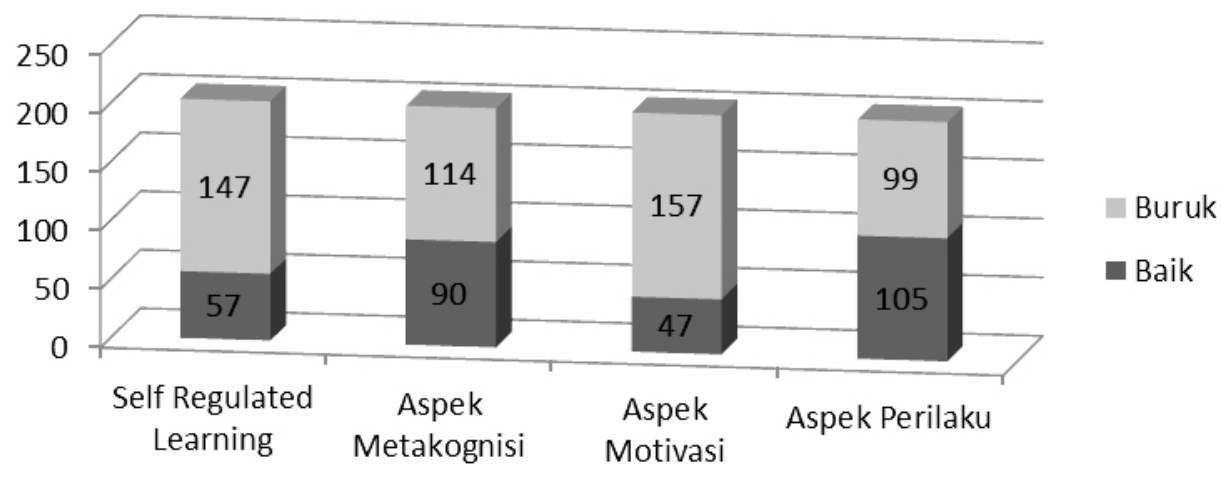

Gambar 1. Diagram Distribusi Frekuensi Self-Regulated Learning dan Aspek-aspek Self-Regulated Learning

Hasil penelitian menunjukkan bahwa 147 orang dari 204 responden $(72,1 \%)$ memiliki SRL yang buruk. Dalam penjabarannya ke dalam aspek-aspek juga menunjukkan hasil yang cukup signifikan pada kategori buruk yaitu pada aspek metakognisi $(55,9 \%)$ dan aspek motivasi (77\%), sedangkan pada aspek perilaku menunjukkan hasil yang tidak signifikan pada kategori baik yaitu 51,1\%.

Aspek metakognisi menunjukkan kemampuan mahasiswa dalam merencanakan belajarnya, menetapkan tujuan dalam belajar, mengatur diri dalam belajar, memonitor diri dalam belajar, dan mengevaluasi diri dalam belajar masih buruk. Hal ini ditunjukkan pada kuesioner yang menyatakan bahwa sebagian besar responden belajar rajin agar cepat menyelesaikan studi, cepat jenuh dan bosan ketika belajar semalam suntuk, mau rajin belajar agar dapat membanggakan orangtua, terbiasa belajar semalam suntuk ketika belajar menghadapi ujian, acuh tak acuh dengan penggunaan strategi belajar yang dipakai selama ini. ${ }^{9,10}$

Pada aspek motivasi demikian juga dengan kemampuan dalam self efficacy, atribusi diri, dan berminat pada tugas intrinsik masih menunjukkan hasil yang buruk. Dalam aspek ini sebagian besar responden kadang-kadang merasa takut dianggap bodoh oleh temannya sehingga malu bertanya ketika mengalami kesulitan, mengeluh sewaktu 
mengerjakan tugas yang sulit dan memandang tugas yang sulit sebagi hambatan dalam proses belajarnya. Selain itu menganggap keberuntungan sebagai faktor yang membantu meraih kesuksesan dalam belajar, dan kurang memiliki motivasi yang tinggi untuk membaca buku tambahan untuk memperluas wawasan. ${ }^{11}$

Aspek perilaku merupakan kemampuan dalam memilih lingkungan yang mengoptimalkan belajar, menstruktur lingkungan yang mengoptimalkan belajar dan menciptakan lingkungan yang mengoptimalkan belajar termasuk kepada kategori baik pada penelitian ini. Hasil yang baik ini ditunjukkan oleh jawaban responden yang mayoritas berusaha menata lingkungan belajar yang kondusif untuk membantu konsentrasi belajar, membuat aktivitas belajar sebagai proses yang menyenangkan, menciptakan lingkungan belajar sesuai kondisi yang diminati, dan mampu memutuskan strategi belajar yang tepat dengan pribadinya dalam menghadapi tugas yang rumit. ${ }^{12}$

Penelitian Jouhari menemukan lima hal utama yang mempengaruhi SRL yaitu keluarga dengan peran supervisi dan dukungan, teman sebaya dengan peran fasilitasi dan inhihisi, instruktur dengan faktor personal dan karakteristik pendidikan instruktur, lingkungan pendidikan dengan faktor fasilitator dan peran inhibisi, dan mahasiswa sendiri dengan faktor fasilitasi dan inhibisi personal. ${ }^{12,13}$

\section{Deskripsi Hasil Belajar Mahasiswa Peserta Bimbingan Persiapan CBT Periode Mei 2018}

Deskripsi frekuensi hasil belajar responden dirangkumkan pada Gambar 2 berikut ini.

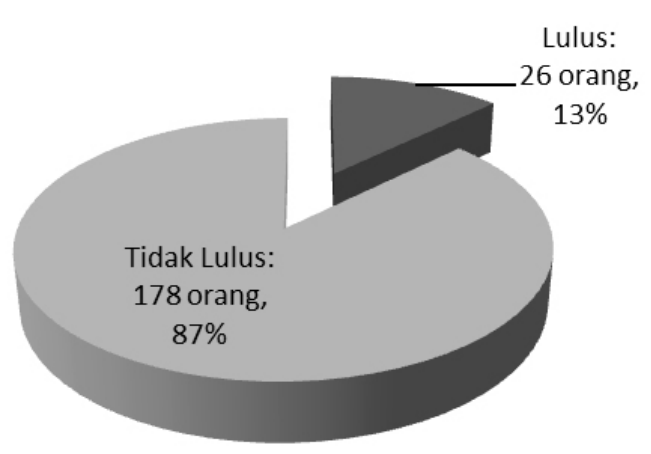

Gambar 2. Hasil Belajar Responden
Hasil penelitian ini menunjukkan tingkat kelulusan yang rendah yang ditunjukkan oleh rendahnya rerata nilai try out CBT yang dapat mencapai angka $\geq 67$ yaitu hanya sebanyak 26 orang dari 204 responden. Nilai rerata try out ini merupakan hasil persiapan mahasiswa selama sekitar 6 minggu yang dikumpulkan dari minimal 3 kali dari 5 try out yang dilakukan selama program kelas regular. Hasil belajar ini menilai ranah kognitif mahasiswa yang berkenaan dengan intelektual yang terdiri atas enam aspek yaitu pengetahuan atau ingatan, pemahaman, dan aplikasi yang termasuk kognitif tingkat rendah, serta analisis, sintesis, dan evaluasi yang termasuk kognitif tingkat tinggi. ${ }^{14}$ Tingkat kelulusan yang rendah ini menunjukkan bahwa responden pada penelitian ini memiliki tingkat kognitif yang rendah pula.

Hasil belajar ini dapat dipengaruhi oleh faktor internal dan eksternal mahasiswa yang bersangkutan. Pencapaian hasil belajar dipengaruhi oleh kecerdasan, bakat, minat dan bakat, motivasi, lingkugan keluarga dan sekolah. Beberapa faktor yang mungkin mempengaruhi hasil belajar yang buruk pada penelitian ini adalah kurangnya disiplin diri dalam belajar di rumah maupun di sekolah, kurangnya kesadaran untuk belajar mandiri, kurang giat belajar, kurang teratur belajar, rasa malas dan bosan belajar di rumah setelah dari sekolah, dan banyaknya waktu kosong yang tidak dimanfaatkan dengan baik. ${ }^{6,15}$

\section{Hubungan Self-Regulated Learning dengan Hasil Belajar Mahasiswa Peserta Bimbingan Persiapan CBT Periode Mei 2018}

Hubungan SRL dan aspek-aspeknya (aspek metakognisi, motivasi, dan perilaku) dengan hasil belajar responden diperoleh dengan analisis bivariat uji hipotesis Chi-Square telah dirangkumkan pada Tabel 2. 
Tabel 2. Hubungan Self-Regulated Learning dengan Hasil Belajar Mahasiswa

\begin{tabular}{|c|c|c|c|c|c|}
\hline \multirow{2}{*}{ Karakteristik } & \multirow{2}{*}{ Kriteria } & \multicolumn{2}{|c|}{ Hasil Belajar } & \multirow{2}{*}{ Total } & \multirow{2}{*}{$\mathrm{p}$} \\
\hline & & Lulus & Tidak Lulus & & \\
\hline \multirow{2}{*}{ Nilai Self-Regulated Learning } & Baik & 8 & 49 & 57 & \multirow{2}{*}{0,731} \\
\hline & Buruk & 18 & 129 & 47 & \\
\hline \multirow{2}{*}{ Aspek Metakognisi } & Baik & 10 & 80 & 90 & \multirow{2}{*}{0,534} \\
\hline & Buruk & 16 & 98 & 114 & \\
\hline \multirow{2}{*}{ Aspek Motivasi } & Baik & 4 & 43 & 47 & \multirow{2}{*}{0,321} \\
\hline & Buruk & 22 & 135 & 157 & \\
\hline \multirow{2}{*}{ Aspek Perilaku } & Baik & 14 & 91 & 105 & \multirow{2}{*}{0,795} \\
\hline & Buruk & 12 & 87 & 99 & \\
\hline
\end{tabular}

Hasil penelitian ini menunjukkan bahwa sebagian besar responden memiliki SRL yang buruk $(72,1 \%)$ dengan hasil belajar yang juga sebagian besar buruk $(87,3 \%)$. Namun, hasil analisis uji chi square pada penelitian ini menyatakan bahwa tidak terdapat hubungan antara SRL dengan hasil belajar atau nilai rerata try out mahasiswa peserta bimbingan persiapan CBT periode Mei 2018 di Klinik UKDI (p value $>0,05$ ). Berbagai aspek SRL juga tidak menunjukkan hubungan dengan hasil belajar responden pada penelitian ini. Dari 57 responden yang memiliki skor SRL yang baik hanya 8 responden yang hasil belajarnya baik (14\%) walaupun dari 147 responden yang memiliki SRL yang buruk, 129 orang menunjukkan hasil belajar yang juga buruk (88\%). Untuk aspek metakognisi, dari 90 responden yang memiliki SRL yang baik hanya 10 orang yang dinyatakan lulus (11\%). Demikian juga pada aspek motivasi, hanya 4 orang yang dinyatakan lulus dari 47 responden yang memiliki SRL yang baik (8,5\%); dan pada aspek perilaku, hanya 14 orang yang memiliki hasil belajar yang baik dari 105 responden yang memiliki SRL yang baik (13\%). Hal ini menunjukkan bahwa responden yang memiliki SRL yang baik tidak lantas menunjukkan hasil belajar yang baik, sehingga kedua variabel ini dinyatakan tidak berhubungan.

Self-regulated learning merupakan kegiatan dimana individu yang belajar secara aktif sebagai pengatur proses belajarnya sendiri, mulai dari merencanakan, memantau, mengontrol dan mengevaluasi dirinya secara sistematis untuk mencapai tujuan dalam belajar, dengan menggunakan berbagai strategi baik kognitif, motivasional maupun behavioral. ${ }^{13,16}$ Dari definisi tersebut dapat dinyatakan bahwa seseorang yang memiliki SRL yang baik seharusnya memiliki hasil belajar yang baik, demikian sebaliknya bila seseorang yang memiliki SRL yang buruk juga akan menunjukkan capaian belajar yang buruk pula. Namun hasil yang berbeda ditunjukkan oleh penelitian ini.

Penelitian yang dilakukan oleh Supriyanto juga menunjukkan bahwa SRL tidak berhubungan dengan prestasi akademik mahasiswa tahun pertama Prodi Psikologi Universitas Pembangunan Jaya (p-value 0,29). ${ }^{8}$ Menurut penelitian tersebut hal ini dapat disebabkan oleh perbedaan individual yang menentukan perbedaan kapasitas SRL. Individu yang berbeda dapat menggunakan strategi belajar yang berbeda ketika menghadapi situasi yang sama. Namun individu yang sama juga dapat menggunakan strategi belajar yang berbeda untuk menghadapi situasi yang berbeda. Kemampuan seseorang untuk belajar, berpikir dan menyelesaikan masalah belajar juga dipengaruhi oleh adaptasi terhadap nilai-nilai, kepercayaan, kebiasaan yang berkembang dalam lingkungan sosial dan budaya mereka. Demikian juga dengan cara orangtua dalam mengarahkan anaknya memecahkan masalah akan mempengaruhi anak tersebut dalam belajar mandiri. ${ }^{16}$

Menurut Stone, Schunk \& Swartz dalam Fasikhah SRL dipengaruhi oleh tiga faktor utama, yaitu keyakinan diri, motivasi dan tujuan. ${ }^{7,13}$ Pada penelitian ini sebagian besar responden menyatakan tujuannya belajar adalah agar cepat menyelesaikan studi (lulus) dan untuk membanggakan orangtua. 
Namun mereka jarang memiliki motivasi yang tinggi untuk membaca buku tambahan untuk memperluas wawasan. Dari hal ini dapat disimpulkan bahwa sebagian besar responden kurang memiliki motivasi internal dan lebih banyak didorong oleh faktor eksternal. Mereka menganggap belajar hanya agar lulus bukan karena ingin menguasai materi secara mendalam.

Penelitian yang dilakukan oleh Nora M. Foerst terdapat diskrepansi antara pengetahuan mahasiswa mengenai SRL dan aplikasinya dalam proses pembelajaran mahasiswa tersebut. Pada penelitian ini dinyatakan bahwa hal tersebut disebabkan oleh beberapa alasan yaitu responden kekurangan waktu untuk mengaplikasikan strategi dalam SRL, strategi SRL tidak sesuai dengan kondisi yang sedang mereka hadapi, ketidakmampuan mengaplikasikan strategi SRL secara efektif, dan merasa kesulitan untuk menggunakan strategi SRL tersebut. ${ }^{17,18}$

\section{KESIMPULAN}

Dalam penelitian ini hubungan SRL dengan rerata nilai try out sebagai hasil belajar dengan uji chi square menunjukkan tidak adanya hubungan dengan $p$ value 0,731 sehingga dapat dinyatakan bahwa tidak terdapat hubungan antara SRL dengan hasil belajar mahasiswa yang mempersiapkan diri untuk ujian CBT periode Mei 2018 pada lembaga bimbingan belajar di kota Medan. Tidak adanya hubungan yang signifikan juga ditunjukkan oleh aspek metakognisi (p-value 0,534) dan aspek perilaku ( $p$-value 0,795), namun penelitian ini menunjukkan adanya hubungan antara aspek motivasi dengan hasil belajar ( $p$-value 0,321 )

Pemahaman yang benar mengenai faktor-faktor yang mempengaruhi SRL menunjukkan bahwa faktor-faktor penunjang sebaiknya diaplikasikan pada individu untuk mengurangi faktor penghambat sehingga akan meningkatkan SRL pada mahasiswa. Dengan demikian dapat disimpulkan bahwa agar SRL dapat mendukung hasil belajar yang baik, maka faktor-faktor yang mempengaruhi baik SRL maupun hasil belajar dari internal dan eksternal dari responden harus saling bersinergi sehingga faktor-faktor yang mempengaruhi tersebut juga saling mendukung dan saling berhubungan.

\section{DEKLARASI KEPENTINGAN}

Penulis menyatakan bahwa manuskrip dan penelitian ini tidak memiliki konflik kepentingan apapun.

\section{DAFTAR PUSTAKA}

1. Presiden Republik Indonesia. Undang-Undang Republik Indonesia Nomor 20 Tahun 2013 Tentang Pendidikan Kedokteran. Presiden Republik Indonesia; 2013.

2. Lidiawati M. Universitas Abulyatama Jurnal Dedikasi Pendidikan Hubungan Bimbingan Belajar UKMPPD dengan Kelulusan UKMPPD Computer Bassed Test Fakultas Kedokteran Universitas Abulyatama Periode Mei 2017. J Dedik Pendidik. 2018;8848(1):63-7.

3. Lisiswanti R, Oktaria D, Sari MI, Prabowo AY. Perbedaan Nilai Sebelum dan Sesudah Bimbingan Metode Small Group Learning dalam Persiapan UKMPPD Nasional Fakultas Kedokteran Universitas Lampung The Difference Between Before and After Guidance Small Group Learning Method of Preparation of National UKMPPD. JK Unila. 2017;1(I):473-7.

4. Demiroren M, Turan S, Oztuna D. Medical Students' Self-Efficacy in Problem-Based Learning and Its Relationship with Self-Regulated Learning. Med Educ Online. 2016;1:1-9.

5. Khoiriyah U, Roberts C, Jorm C, Vleuten CPM Van Der. Enhancing students' Learning in ProblemBased Learning: Validation of a Self-Assessment Scale for Active Learning and Critical Thinking. BMC Infect Dis. 2015;1-8.

6. Sebesta AJ, Speth EB. How Should I Study for the Exam? Self-Regulated Learning Strategies and Achievement in Introductory Biology. CBE- Life Sci Educ. 2017;16(30):1-12.

7. Fasikhah SS, Fatimah S. Self-Regulated Learning (SRL) dalam Meningkatkan Prestasi Akademik pada Mahasiswa. J Ilm Psikol Terap. 2013;01(01):145-55.

8. Supriyanto. Hubungan Antara Self-Regulated Learning dan Prestasi Akademik pada Mahasiswa Semester Pertama Prodi Psikologi Universitas Pembangunan Jaya. J Univ Pembang Jaya. 2015;2(2):49-61.

9. Azmi S. Self Regulated Learning Salah Satu Modal Kesuksesan Belajar dan Mengajar. 2016;19-20.

10. Cosnefroy L, Carré P. Self-regulated and Selfdirected Learning: Why Don't Some Neighbors 
Communicate? Int J Self-directed Learn. 2014;11(2):1-12.

11. Panadero E. A Review of Self-regulated Learning : Six Models and Four Directions for Research. Front Psychol. 2017;8(April):1-28.

12. Artino AR, Hemmer PA, Durning SJ. Using SelfRegulated Learning Theory to Understand the Beliefs , Emotions , and Behaviors of Struggling Medical Students. Acad Med. 2011;86(10):35-8.

13. Jouhari Z, Haghani F, Changiz T. Factors affecting self-regulated learning in medical students: a qualitative study. Med Educ Online. 2017;2981(April):1-8.

14. Sakinnah HR, Permanasari AE, Soesanti I. Support the Learning Process. J Pendidik Sains. 2017;5(1):11-6.

15. Campos-sánchez A, López-núñez JA, Carriel V, Sola T, Alaminos M. Motivational Component
Profiles in University Students Learning Histology : a Comparative Study Between Genders and Different Health Science Curricula. BMC Med Educ. 2014;14(46):1-13.

16. Cazan A, Schiopca B. Self-directed learning , personality traits and academic achievement. Procedia - Soc Behav Sci [Internet]. 2014;127:6404. Available from: http://dx.doi.org/10.1016/j. sbspro.2014.03.327.

17. Foerst NM, Klug J, Jöstl G, Spiel C, Schober B. Knowledge vs . Action : Discrepancies in University Students ' Knowledge about and Self-Reported Use of Self-Regulated Learning Strategies. Front Psychol. 2017;8(July):1-12.

18. Cho KK, Marjadi B, Langendyk V, Hu W. The SelfRegulated Learning of Medical Students in The Clinical Environment - a Scoping Review. BMC Med Educ. 2017;17(112):1-13. 